\title{
ANATOMIA ÓSSEA E MUSCULAR DA ESCAPULA E BRAÇO DE Chrysocyon brachyurus (CARNÍVORA, CANIDAE)
}

\author{
ANATOMY OF BONE AND MUSCLE OF SCAPULA AND ARM OF Chrysocyon \\ Brachyurus (CARNIVORA, CANIDAE)
}

\author{
Saulo Gonçalves Pereira ${ }^{1^{*}}$ \\ André Luiz Quagliatto Santos ${ }^{1}$ \\ Daniela Cristina Silva Borges ${ }^{1}$ \\ Priscilla Rosa Ribeiro Queiroz ${ }^{1}$ \\ José Onício Rosa da Silva² \\ ${ }^{1}$ Universidade Federal de Uberlândia, Uberlândia, MG, Brasil. \\ 2Faculdade Patos de Minas, Patos de Minas, MG, Brasil \\ *Autor para correspondência - saulobiologo@yahoo.com.br
}

\section{Resumo}

O Lobo-guará Chrysocyon brachyurus - Illiger, 1815, é o maior canídeo da América do Sul, distribuindose na região central desse continente, preferencialmente em biomas descampados. Pode atingir entre 20 e $33 \mathrm{~kg}$ e até $125 \mathrm{~cm}$ de altura. Encontra-se em ameaça de extinção. O conhecimento anatômico é de grande importância para a complementação das informações acerca das espécies silvestres e para implicações clínicas, cirúrgicas e conservacionistas. Objetivou-se descrever os ossos e respectivos acidentes ósseos pertencentes ao cíngulo do membro torácico da região braquial e respectivos músculos do lobo-guará, por meio dos procedimentos de dissecação em animais preservados em solução de formol a 10\%. Os animais pertencem ao acervo didático do Laboratório de Ensino e Pesquisa em Animais Silvestres da UFU e são provenientes de atropelamentos. Os ossos são: escápula e úmero. Não foi observada a clavícula. Os músculos são: M. deltoide; M. supraespinhal; M. infraespinhal; M. redondo maior; M. redondo menor; M. tríceps braquial cabeças: lateral, acessória, longa e medial; M. ancôneo; M. bíceps braquial; M. subescapular; M. coracobraquial; M. tensor da fáscia do antebraço; M. braquial. A escápula e o braço têm acidentes específicos, porém são semelhantes aos dos cães domésticos. O úmero é reto. Os músculos apresentam algumas peculiaridades.

Palavras-chave: anatomia; canídeos; lobo-guará; miologia; osteologia.

\begin{abstract}
The maned wolf, Chrysocyon brachyurus - Illiger, 1815, is the largest canid of South America and its found in the central region of the continent, preferably in open field biomes. It may reach between 20 and $33 \mathrm{~kg}$ and up to $125 \mathrm{~cm}$. It is under threat of extinction. Anatomical knowledge is of great importance to the completion of information about wild species and clinical, surgical, and conservationist implications. This study aimed to describe the bones and the bone accidents of the cingulate forelimb of brachial region and their respective muscles in maned wolf, through dissection procedures of animals preserved in $10 \%$ formalin solution. The animals belong to the didactic collection of the Laboratory of Education and Research on Wild Animals of UFU, and are the result of roadkill. The bones are scapula and humerus. There was no clavicula. The muscles are: M. deltoideus; M. supraspinatus; M. infraspinatus; M. teres major; M. teres minor; M. triceps brachii caput: laterale,
\end{abstract}


accessorium, longum and mediale; $\mathrm{M}$. anconeus; M. biceps; M. subscapularis; M. coracobrachialis; M. tensor fasciae antebrachii; M. brachial. The scapula and arm have specific accidents; however, they are similar to domestic dogs. The humerus is straight. The muscles have some peculiarities.

Keywords: anatomy; canids; maned wolf; muscles; osteology.

Enviado em: 10 dezembro de 2015

Aprovado em: 09 agosto de 2016

\section{Introdução}

A anatomia macroscópica serve como ferramenta fundamental para a descrição de uma espécie e para a comparação entre espécies morfologicamente parecidas. Apesar das semelhanças anatômicas entre os cães domésticos e os canídeos selvagens, há peculiaridades na descrição de espécies selvagens. Dessa maneira, o conhecimento de sua anatomia muscular e óssea é de grande importância ${ }^{(1,2)}$.

Chrysocyon brachyurus - Illiger, 1815 - pertence à ordem Carnívora e à família Canidae, que possui 13 gêneros e 35 espécies $^{(3)}$. É encontrado na Terra desde o período Pleistoceno até os dias atuais, sua filogenia está próxima à dos cães-do-Pólo-Norte, raposa-do-campo (Pseudalopex vetulus - Lund, 1842) raposinha (Lycalopex vetulus- Lund, 1842 - que é o único canídeo unicamente brasileiro) e, por fim, o cachorro-do-mato (Cerdocyon thous- Linnaeus, 1766) ${ }^{(4)}$. Habita áreas de vegetação aberta principalmente no Cerrado, Pampas e Caatinga com menor frequência na Floresta Atlântica, ainda há ocorrência na Argentina, Bolívia, Paraguai, Peru, Uruguai. Está classificado como vulnerável em extinção ${ }^{(3)}$.

Os membros torácicos de $C$. brachyurus são longos, o que auxilia o animal em uma melhor perspicácia visual, maior aceleração, dentre outros fatores. A disposição dos ossos dos membros possibilita sua movimentação em descampados de grande extensão, porém apresenta certa dificuldade para descer ${ }^{(5)}$. Não há dimorfismo sexual aparente.

Com relação ao seu passo, C. brachyurus é classificado como cursorial digitígrado e o seu passo é único entre os canídeos, pois seu andar é "compassado", no qual os membros torácicos e pélvicos, do mesmo lado, se movem ao mesmo tempo. É possível que essa movimentação de andadura seja mais eficiente na manutenção de energia através dos caminhos de gramíneas altas do habitat nativo, representando, assim, sua postura com ossos finos e alongados com possibilidade de aceleração e saltos ${ }^{(6-8)}$.

Visto a importância de C. brachyurus para o meio ambiente, como predador de pequenos animais e dispersor de sementes, considerando, ainda, o conhecimento anatômico sobre a espécie para os apontamentos de ordem clínica, cirúrgica (sobretudo, em função dos vários acometimentos e fraturas ósseas que são bastante recorrentes, muitas devido aos atropelamentos) e conservacionista, objetivou-se descrever os principais acidentes ósseos e os músculos da escápula e braço de C. brachyurus.

\section{Material e Métodos}

Foram utilizados os membros torácicos de $C$. brachyurus de três espécimes adultos, que se encontravam fixados em solução aquosa de formaldeído a $10 \%$ e conservados em cubas opacas contendo a mesma solução. Tais animais, que fazem parte do seu acervo permanente do Laboratório de Ensino e Pesquisa em Animais Silvestres da Universidade Federal de Uberlândia (LAPAS-UFU), são provenientes de atropelamento.

Para a descrição muscular, inicialmente, foi feita a retirada da pele e do excesso de tecido adiposo do membro torácico de três indivíduos. Os músculos foram expostos e dissecados, segundo as técnicas usuais 
em anatomia macroscópica, observando-se a origem, inserção e distribuição muscular. Para a descrição dos ossos, os membros torácicos de três animais foram macerados por cocção com ebulidor elétrico em balde plástico de 20 litros com água fervente e posteriormente depositados em solução de peróxido de hidrogênio (50\% PA). Depois de limpos e secos, os ossos foram identificados e minuciosamente descritos.

A pesquisa está de acordo com a Instrução Normativa 03/2015 do IBAMA e está protocolada no Comitê de Ética na Utilização de Animais UFU 087/16. Os dados foram discutidos e as descrições estão apresentadas, de acordo com os termos recomendados pelo International Committee on Veterinary Gross Anatomical Nomenclature ${ }^{(9)}$. As imagens foram registradas com câmera digital, as fotos foram tratadas pelo software Photoshop CS (2012®).

\section{Resultados e Discussão}

O osso escápula de $C$. brachyurus tem duas faces, três ângulos e três bordas (Figura 1- A, B, C). É um osso plano, triangular e estreito. Existe uma acentuada diferença entre o ângulo cranial que é arredondado e o ângulo caudal que é projetado sobe a quarta costela. Na face lateral em sua região média, de forma oblíqua, encontra-se a espinha da escápula, que aumenta gradativamente de altura no sentido dorsoventral e divide esta face em duas fossas (fossa supra e infraespinhal). Nesta espinha da escápula, em C. brachyurus, inserem-se os músculos omostransverso, deltoide e trapézio. A fossa infraespinhal é mais larga e em sua extremidade apresenta o ângulo caudal bem definido além da fossa supraespinhal que é mais estreita com borda arredondada. Esta configuração também é observada em cão-doméstico (Canis lupus familiaris - Linnaeus 1758) ${ }^{(10-13)}$, paca (Agouti paca) ${ }^{(14)}$ e cachorro-do-mato (15).

A borda cranial é fina e convexa, enquanto a borda caudal é reta e mais espessa. A borda dorsal é, também, convexa e espessa e é circundada por uma faixa de cartilagem escapular. O colo da escápula é bem nítido (Figura 1 - A, B, C), no ângulo ventral, há a cavidade glenoidal, uma superfície lisa, oval e côncava que se articula com o úmero. Situada craniodorsalmente a esta cavidade, há uma saliência rugosa, o tubérculo supraglenoidal, do qual se destaca o processo coracoide. Há um número variável de forames nutrícios no colo da escápula. Na face costal encontra-se a fossa subescapular que é extremamente rasa e áspera com demarcação pouco nítida e na porção proximal cranial a face serrátil, a mesma conformação pode ser encontrada em Cerdocyon thous ${ }^{(15)}$.

Na extremidade distal, no ângulo ventral, está presente o acrômio, que é curto e está oposto à borda da cavidade glenoidal, ainda no acrômio. Percebe-se, assim como nos felinos, o processo hamato (ventral) e o processo supra-hamato (dorsal), que dá inserção do músculo deltoide parte acromial ${ }^{(10,14)}$. C. brachyurus, assim como alguns carnívoros corredores, tem o movimento do passo como cursorial digitígrado e, dessa maneira, a escápula sendo livre de movimento facilita o desenvolvimento de uma aceleração efetiva juntamente com os músculos do cíngulo, dando sustentação para atividades de saltar e pular. Ressalta-se que a escápula alongada facilita tais movimentos em função da ausência da clavícula $(7,16,17)$.

O osso úmero de C. brachyurus (Figura 2 - A, B) possui duas extremidades (proximal e distal), diáfise e faces cranial, medial, lateral e caudal, articula-se com a cavidade glenoidal na sua região proximal para formar o ombro e distalmente com os ossos rádio e ulna formando o cotovelo. É longo e apresenta um tênue giro espiral. Seu corpo apresenta-se levemente comprimido lateralmente, especialmente nos seus dois terços proximais. Comparado ao úmero do C. familiaris, não é tão encurvado e convexo cranialmente ${ }^{(10)}$. 


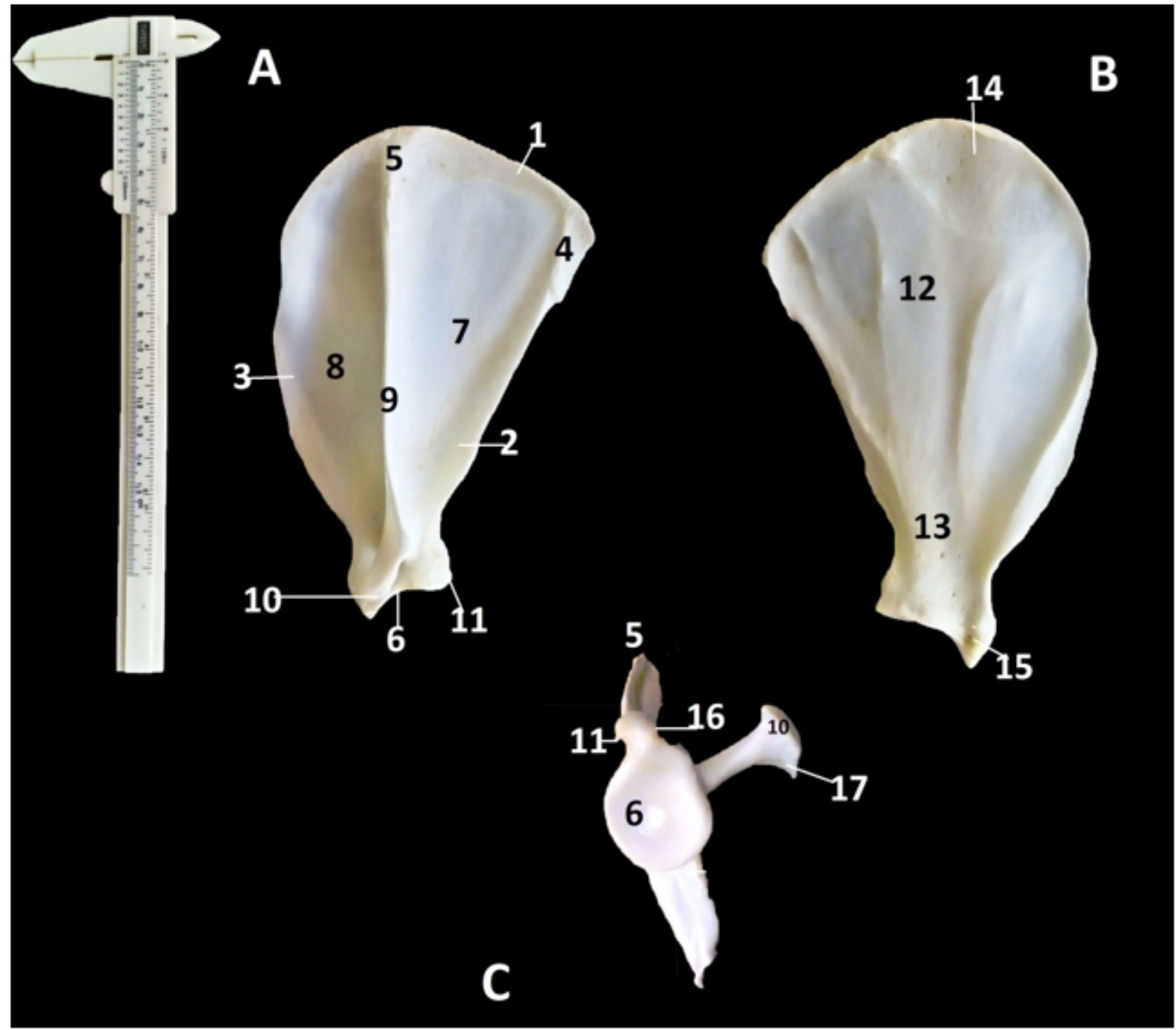

Figura 1. Escápula de C. brachyurus: A - face lateral. B - face costal. C - face ventral. 1Borda dorsal; 2- Borda caudal; 3- Borda cranial; 4- Ângulo caudal; 5- Ângulo cranial; 6Ângulo ventral (cavidade glenoidea); 7- Fossa infraespinhal; 8- Fossa supraespinhal; 9Espinha da escápula; 10- Acrômio; 11- Tubérculo infragleinoide; 12- Fossa subescapular; 13Colo da escápula e Forame Nutrício; 14- Face serrátil; 15- Processo coracoide; 16- Tubérculo supragleinoide; 17- Processo hamato.

$\mathrm{Na}$ extremidade proximal, localiza-se a cabeça do úmero, que é acentuadamente curvada craniocaudalmente e limitada ventralmente por um colo bem delineado (Figura 2-A, B). Ainda na cabeça encontram-se o tubérculo maior, que está disposto craniolateralmente próximo à cabeça do osso e não apresenta divisões, e o tubérculo menor, situado na face lateral da extremidade proximal do úmero, pouco evidente e repleto de forames nutrícios, principalmente em sua face medial, e que também não é dividido. O sulco intertuberal inicia-se na extremidade cranial da área articular e aloja o tendão de origem do musculo bíceps braquial. O sulco do músculo braquial é uma depressão rasa e lisa na face lateral do úmero, assim como para cães ${ }^{(10)}$.

A face cranial em sua porção distal estreita-se até a tróclea do úmero, onde se encontra a crista do tubérculo maior (Figura 2). A tuberosidade deltoidea localiza-se na face lateral da extremidade proximal, distalmente ao tubérculo maior que é convexo e dá inserção dos músculos supra e infraespihal, e é pouco evidente comparando-se ao cão. $\mathrm{O}$ forame nutrício situa-se aproximadamente no terço médio da face caudal. O sulco do músculo braquial é uma depressão rasa e lisa na face lateral do úmero, assim como para Canis lupus familiaris ${ }^{(18)}$. A crista epicondilar é pouco evidente. 
A face caudal é lisa e termina estreitando-se na fossa do olecrano. Já na face medial, assim como para cães, a crista do tubérculo menor liga-se à tuberosidade redonda maior. Nesta região inserem-se os músculos grande dorsal e redondo maior e está pouco evidente em lobo-guará( ${ }^{(11,18)}$.

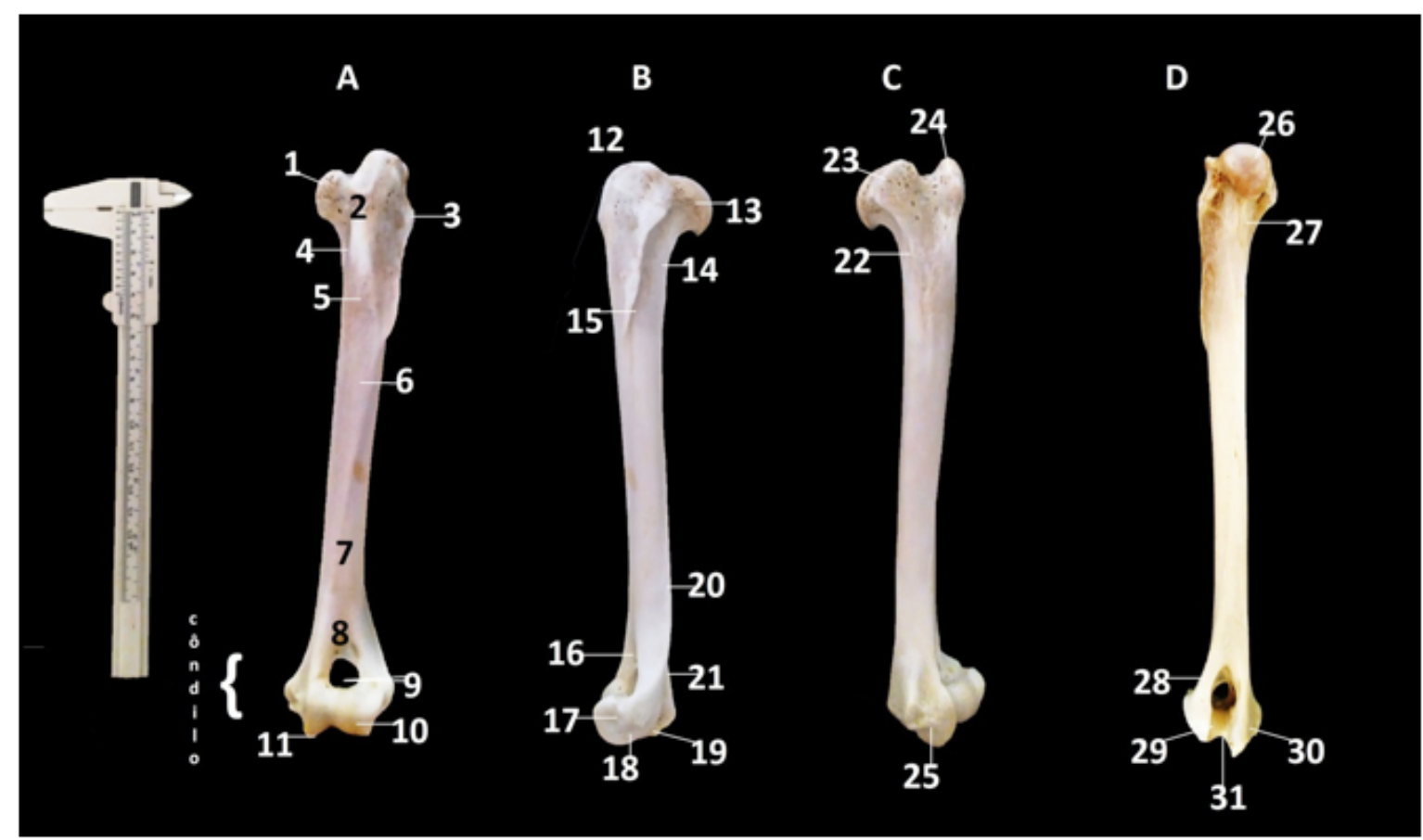

Figura 2. Úmero de C. brachyurus: A - Face Cranial; B - Face Lateral; C - Face Medial; D - Face caudal. 1, 23, 27- Tubérculo menor; 2, 12, 24- Tubérculo maior; 3Tuberosidade do musculo redondo menor; 4- Crista do tubérculo maior; 5, 22- Tuberosidade do M. redondo maior; 6, 15- Tuberosidade deltoide;7- Sulco do M. braquial; 8, 16- Fossa radial; 9- Forame supratroclear; 10-Capítulo; 11, 17, 25- Tróclea; 13, 26- Cabeça; 14- Colo; 18, 29- Epicôndilo Lateral; 19, 30- Epicôndilo medial; 20- Corpo; 21, 31- Fossa do Olecrano; 28 Crista supracondilar lateral.

Ossos alongados e retos dão para esta espécie algumas funcionalidades adaptativas, tais como, deslocamento por grandes áreas, velocidade, capacidade de saltos e de sustentação. Essas adaptações fazem parte de seu comportamento ${ }^{(19,20)}$. O côndilo divide-se em tróclea do úmero, capítulo, fossa radial e olecrano.

Em C. Brachyurus, o sulco que divide a tróclea do úmero e o capítulo é bastante proeminente, diferentemente do que é descrito para cães ${ }^{(10)}$. Tal característica favorece as alavancas para um maior ganho no passo $^{(21)}$. A fossa radial é uma depressão rugosa, na porção cranial do osso úmero, localizada acima da tróclea do úmero. A fossa do olecrano, situada na porção caudal, abriga parte do osso ulna. Estas fossas comunicam-se através do forame supracondilar, bem desenvolvido em carnívoros. Os epicôndilos são o medial na face medial da extremidade distal e o epicôndilo lateral proximal ao capítulo, que são bem nítidos, sobretudo o epicôndilo medial ${ }^{(18,11,12)}$.

Os músculos são as unidades ativas de trabalho dos animais e, por meio dos movimentos de contrações e relaxamentos de suas fibras, harmonizam os movimentos de flexão, extensão, rotação, adução e abdução do membro ${ }^{(22)}$. Os músculos da escápula, ombro e braço de $C$. brachyurus originam-se na escápula e se inserem no úmero. Dividem-se na face lateral e face medial da escápula e úmero. Os músculos laterais da escápula (Figura 3- A) compreendem os músculos supraespinhal, deltoide, infraespinhal e redondo menor. 


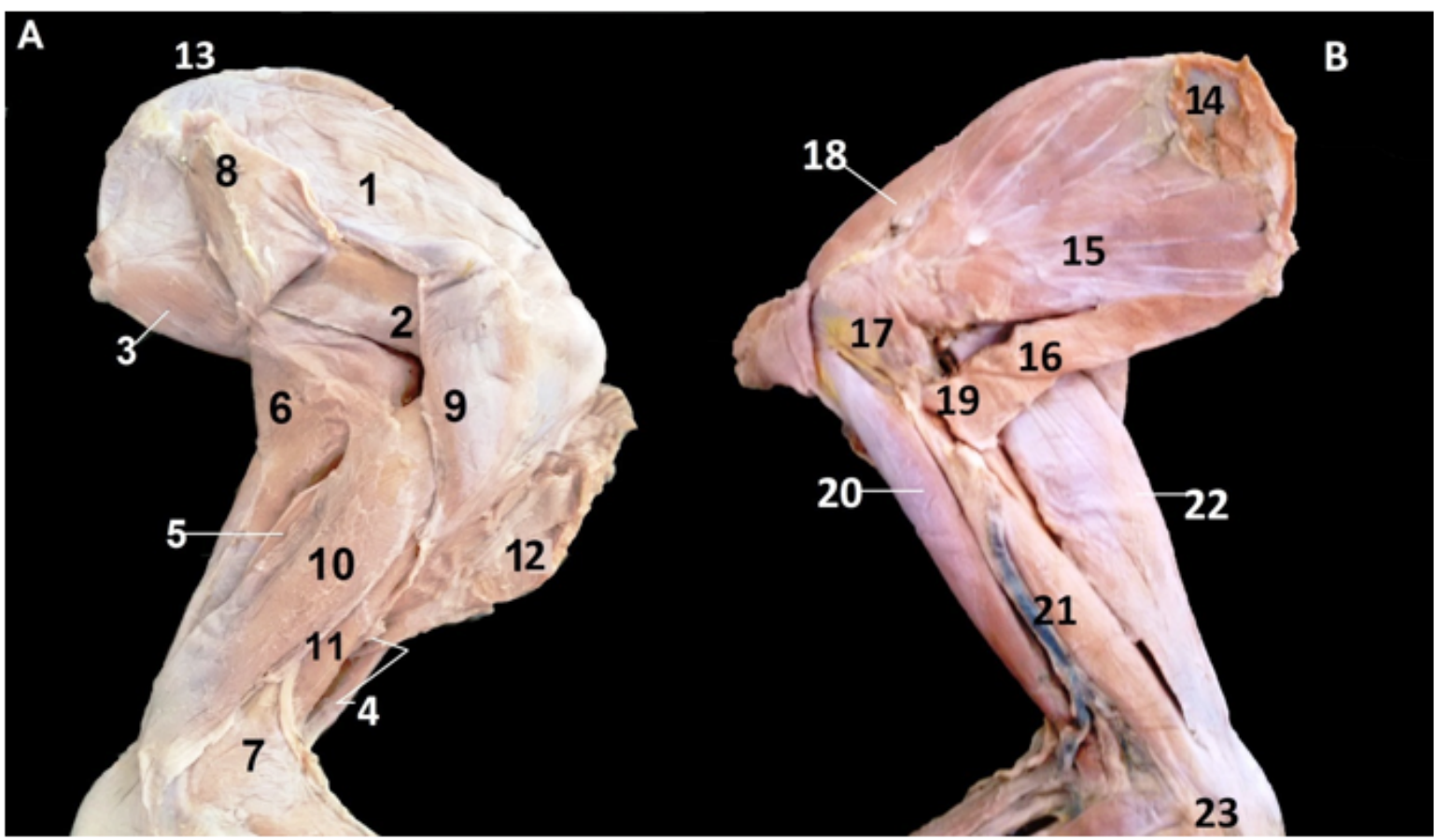

Figura 3: Músculos de ombro de braço de C. brachyurus - A- Vista Lateral, B- Vista Medial 1- M. Supraespinhal; 2- M. Infraespinhal; 3- M. Redondo maior; 4- M. Bíceps braquial; 5- M. Tríceps braquial cabeça acessória; 6- M. Tríceps braquial cabeça lateral; 7- M. Ancôneo; 8- M. Deltoide porção escapular [parcialmente rebatido]; 9- M. Deltoide porção acromial; 10- M. Tríceps braquial cabeça longa; 11- M. Bíceps braquial; 12- M. Braquicefálico [parcialmente rebatido]; 13- Ângulo cranial da escápula; 14- Face Serrátil; 15M. Subescapular, 16- M. Redondo maior; 17- M. Coracobraquial; 18- M. supraespinhal; 19M. Grande Dorsal [parcialmente rebatido]; 20- M. Bíceps braquial; 21- M. Tríceps braquial cabeça medial; 22- M. Tensor da fáscia do antebraço; 23- Olecrano.

O M. Supraespinhal origina-se e se localiza na fossa supraespinhal da escápula, está localizado profundamente ao M. trapézio e M. omotransversal, insere-se por um tendão no tubérculo maior do úmero, é longo, profundo e sinergista do ombro. Semelhança a essa anatomia também foi encontrada em Cerdocyon thous ${ }^{(23)}$, em Nasua Nasua ${ }^{(24)}$ e na onça-parda - Puma concolor - Kerr, $1792^{(25)}$.

O M. Infraespinhal (3 2A) origina-se e localiza-se na fossa infraespinhal da escápula, insere-se na parte caudal do tubérculo maior do úmero, está profundo ao M. Deltoide, é sinergista da articulação do ombro e é um músculo plano. Este músculo funciona como um ligamento colateral lateral da articulação do ombro assim como para outros carnívoros ${ }^{(26)}$.

O M. redondo menor (Figura 3-A) é pouco evidente em C. brachyurus, é curto, origina-se na borda caudal da escápula e se insere-se na tuberosidade do redondo menor no úmero, assim como para mãopelada (Procyon cancrivrus- Cuvier, 1798) ${ }^{(27)}$, semelhante ao Canis lupus familiaris ${ }^{(11)}$ e ao Nasua nasua $^{(24)}$

O M. Deltoide (Figura 3) situa-se lateralmente à escápula, assim como em Canis lupus familiaris, gato (Felis catus - Lineus 1758) ${ }^{(28,29)}$, em quati (Nasua nasua) ${ }^{(24)}$ e em Cerdocyon thous ${ }^{(23)}$ e divide-se em duas partes (porção proximal e distal). Em C. brachyurus a porção proximal origina-se na espinha da escápula e a porção acromial (distal) origina-se na região do acrômio junto ao processo hamato. Ambas as porções inserem-se na tuberosidade deltoidea na face lateral do úmero. Com relação à sua ação, infere-se que auxilie juntamente com o M. cleidobraquial na movimentação e deslocamento em função da ausência da clavícula. 
Os músculos laterais da escápula (Figura 3- A) são: M. subescapular; M. redondo maior e M. coracobraquial. O M. redondo maior (Figura 3- B) origina-se no ângulo caudal da escápula e inserese na tuberosidade do redondo maior do úmero. É um músculo alongado; apesar de ser chamado redondo não é arredondado, diferentemente de Canis lupus familiaris que é afinalado na extremidade distal.

O M. subescapular (Figura 3- B) localiza-se na fossa subescapular e parte da face serrátil da escápula. É um músculo plano com várias inervações longitudinais em direção à inserção do músculo que se localiza no tubérculo menor do úmero. Ele ocupa apenas essa fossa, diferentemente do observado em Cerdocyon thous que ocupa uma área maior que a da fossa subescapular ${ }^{(23)}$.

O M. coracobraquial (Figura 3- B) em C. brachyurus é um músculo pouco evidente, alongado, que tem sua origem em um estreito tendão a partir do processo coracóide da escápula e insere-se profundamente ao M. Tríceps braquial cabeça lateral. Este músculo é, também, alongado para auxiliar no posicionamento de extensão do ombro; no entanto, sua ação é aparentemente restrita ${ }^{(29)}$.

Os músculos do braço de C. brachyurus são, em sua parte cranial, o M. bíceps braquial e o M. braquial e, em sua face caudal, o M. tensor da fáscia do antebraço, o M. Tríceps braquial e o ancôneo.

O M. bíceps braquial (Figura 3- A, B) de C. brachyurus origina-se como um tendão proeminente a partir do tubérculo supragleinodal da escápula. É um músculo tendíneo em sua porção muscular, é fusiforme e alongado onde tem uma fáscia tênue lateralmente, com a mesma conformação que Canis lupus familiaris ${ }^{(30)}$. Insere-se na tuberosidade ulnar e radial por dois tendões fibrosos. Um padrão encontrado nessa espécie foi o de músculos alongados, assim como seus ossos. Acredita-se que esta condição corpórea dê ao animal a possibilidade de ter membros também alongados, o que proporciona uma melhor capacidade visual, dentre outros fatores. Carnívoros arborícolas como Nasua nasua tem esse músculo menos alongado ${ }^{(24)}$. A ação descrita para Canis lupus familiaris de flexionar a articulação do cotovelo e estender a articulação do ombro também descreve C. brachyurus ${ }^{(18)}$.

O M. braquial (Figura 3- A, B) está localizado no sulco do M. braquial, em C. Brachyurus, e cruza a articulação do cotovelo. Este músculo tem uma parte que está profunda ao M. cíceps braquial e, juntamente com este, insere-se na tuberosidade da ulna, diferentemente do descrito para Canis lupus familiaris que tem sua inserção no rádio ${ }^{(18)}$.

M. tensor da fáscia do antebraço (Figura 3- A, B) é alongado e está superficialmente situado em $C$. brachyurus sobre o M. tríceps braquial cabeça longa. Sua origem é na margem caudal da escápula e tem sua inserção no olecrano. Assim como em outros canídeos, acredita-se que, em função de sua posição, o M. tensor da fáscia do antebraço flexiona a articulação do ombro e tenciona a fáscia antebraquial $^{(11)}$.

O M. tríceps braquial (Figura 3- A, B) de C. brachyurus está dividido em quatro partes (cabeças): longa, lateral, acessaria e medial; no entanto com três inserções no olecrano. A porção longa é mais protuberante e, como o próprio nome diz, mais alongada que as demais. Esta porção origina-se na borda caudal da escápula. Em seu corpo alongado existem fibras direcionadas tendíneas que formam um forte tendão que se inserem na parte caudal do olecrano. De acordo com sua posição, infere-se que, assim como com outros canídeos, tenha a função de flexionar a articulação do ombro ${ }^{(10-12,18)}$. A parte lateral do tríceps-braquial origina-se no úmero por uma aponeurose fina na cabeça lateral do úmero e se insere juntamente com o tendão da porção longa. A porção medial do M. tríceps-braquial de C. brachyurus é pouco evidente e está aderida à porção longa. Diferentemente de Canis lupus familiaris e Cerdocyon thous, sua origem é na tuberosidade redonda do úmero e se insere também no forte tendão da porção longa. Em C. Brachyurus, a porção acessória é pouco evidente, originando-se na parte caudal do úmero e estendendo-se como um músculo tendíneo, que se insere juntamente com as outras partes no olecrano. No lobo-guará, assim como outros mamíferos, o M. tríceps-braquial é o mais evidente na região do braço, destacando-se o posicionamento das fibras e a forma alongada dos músculos, o que pode contribuir para a corrida ${ }^{(12)}$. M. ancôneo (Figura 3- A, B) é um músculo largo, porém, alongado. Em C. Brachyurus, tem sua origem no epicôndilo lateral do úmero e se insere no corpo da ulna e não na extremidade proximal da ulna como descrito para cães ${ }^{(11)}$. 
O Quadro a seguir apresenta os pontos de fixação (origem e inserção) e a inferência da ação dos músculos do cíngulo escapular e braço de $C$. brachyurus, com base nos pontos de fixação, direção de fibras e o que é descrito pela literatura para outros canídeos.

Quadro 1. Origem, inserção e inferência da ação dos músculos do cíngulo escapular e braço de C. brachyurus

\begin{tabular}{|c|c|c|c|}
\hline Músculos & Origem & Inserção & Inferência de ação \\
\hline M. Deltoide & $\begin{array}{l}\text { Porção proximal: espinha da } \\
\text { escápula; Porção distal: Acrômio e } \\
\text { processo hamatus }\end{array}$ & Tuberosidade deltoide & Flexionar o ombro \\
\hline M. Supraespinhal & Cartilagem da escápula & Tubérculo menor & $\begin{array}{l}\text { Estender a articulação do } \\
\text { ombro }\end{array}$ \\
\hline M. Infraespinhal & Fossa infraespinhal & $\begin{array}{l}\text { Tubérculo maior do } \\
\text { úmero }\end{array}$ & $\begin{array}{l}\text { Estender e flexionar o } \\
\text { ombro. }\end{array}$ \\
\hline M. Redondo menor & Tubérculo infragleinodal & $\begin{array}{l}\text { Tuberosidade do } \\
\text { redondo menor }\end{array}$ & $\begin{array}{l}\text { Flexionar a articulação do } \\
\text { ombro }\end{array}$ \\
\hline M. Subescapular & Fossa subescapular & $\begin{array}{l}\text { Tubérculo menor do } \\
\text { úmero }\end{array}$ & Aduzir e estender o ombro \\
\hline M. Redondo maior & Borda caudal da escápula & $\begin{array}{l}\text { Tuberosidade do } \mathrm{M} \text {. } \\
\text { redondo maior no } \\
\text { úmero }\end{array}$ & $\begin{array}{l}\text { Flexionar a articulação do } \\
\text { ombro e aduzir o braço }\end{array}$ \\
\hline M. Coracobraquial & Processo coracóide da escápula & $\begin{array}{l}\text { Crista do tubérculo } \\
\text { menor no úmero }\end{array}$ & $\begin{array}{l}\text { Aduzir o braço e estender } \\
\text { o ombro }\end{array}$ \\
\hline M. Biceps braquial & $\begin{array}{l}\text { Ambas partes no Tuberosidade } \\
\text { supragleinodal }\end{array}$ & $\begin{array}{l}\text { Tuberosidade ulnar e } \\
\text { radial }\end{array}$ & $\begin{array}{l}\text { Flexionar a articulação do } \\
\text { cotovelo estender ombro }\end{array}$ \\
\hline M. Braquial & $\begin{array}{l}\text { Terço proximal da superficie } \\
\text { lateral do úmero }\end{array}$ & $\begin{array}{l}\text { Tuberosidade ulnar e } \\
\text { radial }\end{array}$ & $\begin{array}{l}\text { Flexionar a articulação do } \\
\text { cotovelo }\end{array}$ \\
\hline \multirow{4}{*}{ M. Tríceps do braço } & $\begin{array}{l}\text { Cabeça longa: borda caudal da } \\
\text { escápula }\end{array}$ & Olecrano & $\begin{array}{l}\text { Estender a articulação do } \\
\text { cotovelo e flexionar a } \\
\text { articulação do ombro }\end{array}$ \\
\hline & $\begin{array}{l}\text { Cabeça lateral: Linha do } \mathrm{M} \text {. } \\
\text { tríceps no úmero, imediatamente } \\
\text { distal ao tubérculo menor }\end{array}$ & Olecrano & $\begin{array}{l}\text { Estender a articulação do } \\
\text { cotovelo }\end{array}$ \\
\hline & Cabeça medial: Tubérculo menor & Olecrano & $\begin{array}{l}\text { Estender a articulação do } \\
\text { cotovelo }\end{array}$ \\
\hline & Cabeça acessória: Colo do úmero & Olecrano & $\begin{array}{l}\text { Estender a articulação do } \\
\text { cotovelo e flexionar o } \\
\text { ombro }\end{array}$ \\
\hline $\begin{array}{l}\text { M. Tensor da fáscia } \\
\text { do antebraço }\end{array}$ & Face lateral do M. Grande dorsal & Olecrano & $\begin{array}{l}\text { Estender a articulação do } \\
\text { cotovelo }\end{array}$ \\
\hline M. Ancôneo & Epicôndilos medial e lateral & $\begin{array}{l}\text { Extremidade proximal } \\
\text { da ulna }\end{array}$ & $\begin{array}{l}\text { Estender a articulação do } \\
\text { cotovelo }\end{array}$ \\
\hline
\end{tabular}




\section{Conclusão}

A escápula e o braço de $C$. brachyurus têm acidentes específicos; no entanto, são semelhantes aos dos cães domésticos. Existe uma marcante diferença entre o ângulo cranial e o ângulo caudal da escápula e há presença de processo hamato. O úmero é reto, o sulco que divide a tróclea e o capítulo é bastante proeminente. Os músculos apresentam similaridades com o cão-doméstico e outros canídeos silvestres e domésticos. O M. deltoide em sua porção acromial origina-se na região do acrômio junto ao processo hamato. A inserção do M. braquial é na tuberosidade da ulna. O M. ancôneo insere-se no epicôndilo lateral. As principais diferenças morfológicas de $C$. brachyurus apoiam a inferência que a estrutura anatômica da escápula e do braço é adaptada funcionalmente para esta espécie.

\section{Referências}

1. Tavares EMM. et al. Origem e distribuição do nervo toracodorsal em fetos de suínos da linhagem Pen Ar Lan. Revista Biotemas, 2012; 1(25):211-217, Disponível em: < https://periodicos.ufsc.br/index.php/biotemas/ article/view/2175-7925.2012v25n1p111>. Acesso em: 15 de Agosto de 2015.

2. Lima FC. et al. Muscular anatomy of the pectoral and forelimb of Caiman crocodilus crocodilus (Linnaeus, 1758) (Crocodylia: Alligatoridae). Ciênc. Anim. Bras., 2016;17(2):285-295. Disponível em: < http://www. scielo.br/scielo.php?script=sci_arttext\&pid=S1809-68912016000200285 $>$. Acesso em: 15 de Setembro de 2015.

3. Cubas ZS, Silva JCR, Catão-Dias JL. Tratado de animais selvagens: Medicina Veterinária. $1^{\text {a }}$ Edição. São Paulo: Ed Roca, 2007. 523-677. Português.

4. Slater GJ, Thalmann OL, Jennifer A, Schweizer RM, Koepfli K P, Pollinger JP, Rawlence NJ, Austin JJ, Cooper A, Wayne RK. Evolutionary history of the Falklands wolf. Current biology. 200919 (20) p. R937-R938. Disponível em: < http://dx.doi.org/10.1016/j.cub.2009.09.018> . Acesso em 01 de Abril de 2016.

5. Motta-Junior JC, Talamoni SA, Lombardi JA \& Simokomaki K. Diet of the Maned Wolf, Chrysocyon brachyurus, in Central Brazil. Journal of Zoology. 1996;240: 277-284.

6. Shaw JH, Carter TS, Machado-Neto JC. Ecology of the Giant Anteater Myrmecophaga tridactyla in Serra as Canastra, Minas Gerais, Brazil: A Pilot Study. In: Evolution and Ecology of Sloths, Armadillos, and Vermilinguas (G. G. Montgomery, ed.). Smithsonian Institution Press, pp. 379- 384,. 1995

7. Hildebrand G, Goslow G. Análise da Estrutura dos Vertebrados. $2^{\mathrm{a}}$ Ed.). Editora Atheneu SP. Português. 2006

8. Rodden M, Rodrigues F, Bestelmeyer S. Chrysocyon brachyurus. IUCN. Lista Vermelha de Espécies Ameaçadas da IUCN de 2012 Versão 2, 2008.

9. INTERNATIONAL COMMITTEE ON VETERINARY GROSS ANATOMICAL NOMENCLATURE. Nomina anatomica veterinária. 5. ed. (rev.) Knoxville: World Association on Veterinary Anatomist, 2012. 177 p.

10. Zamith APL. Lições de osteologia dos animais domésticos. An. Esc. Super. Agric. Luiz de Queiroz [online]. 1946, vol.3, pp. 173-270. ISSN 0071-1276.

11. Evans HE, De La Hunta A. Miller guia para dissecação do cão. 3.ed. Rio de Janeiro: Guanabara Koogan, 1994. p. 04-55. Português 
12. CONFEDERAÇÃO BRASILEIRA DE CINOFILIA (CBKC) "Manual de Estrutura e Dinâmica do Cão"Conselho Cinotécnico da CBKC -3 $3^{\mathrm{a}}$ edição - 2003.

13. Oliveira FS, Canola JC, Machado MRF, Camargo MHB.. Descrição anátomo-radiográfica do esqueleto apendicular da paca (Agouti paca). Acta Scientiae Veterinariae. 35: 83-87. Disponível em: $<$ www.arsveterinaria. org.br/index.php/ars/article/viewFile/162/179>. 2007. Acesso em 02 de Fevereiro de 2016.

14. Budras KD, Fricke W. Anatomy of the dog: an illustrated text. London, Inglaterra: Mosby-Wolf. 1995.

15. Pinheiro LL. et al. Descrição do plexo braquial do cachorro-do-mato (Cerdocyon thous - Linnaeus, 1766). Ciênc. anim. bras. 2014;15(2):213-219. Disponível em: < www.scielo.br/pdf/cab/v15n2/a13v15n2.pdf $>$. Acesso em 02 de Fevereiro de 2016.

16. Canapp Junior SO. Injuries in sporting and working dog. Proceeding of the NAVC North American Veterinary Conference. Orlando, Flórida, p.1314, 2007a.

17. Canapp Junior SO. Rotator Cuff Injury in performance dogs. Clean Run. Ed.13 v.(2), p.2-5, 2007b. Disponível em: < http://www.vosm.com/upload/Rotator-Cuff-Injury.pdf >. Acesso em 02 de Fevereiro de 2016.

18. Getty R. Anatomia dos animais domésticos. 5a Edição. Rio de Janeiro: Ed Guanabara Koogan, 1986. 13371440 pgs. Português.

19. Dietz JM. Ecology and Social Organization of the Maned Wolf. - Smithsonian Contributions to Zoology, 1984:392 : 1 - 51. Disponível em: < https://www.researchgate.net/publication/36340603 Ecology and social_organization of the maned_wolf Chrysocyon brachyurus microform $>$. Acesso em 02 de Fevereiro de 2016.

20. Dietz JM. 1985. Chrysocyon brachyurus. Mammalian Species, 234: 1-4.

21. Ribeiro PRQ et. al. Movement anatomy of the gluteal region and thigh of the giant anteater Myrmecophaga tridactyla (Myrmecophagidae: Pilosa). Pesq. Vet. Bras. [online]. 2016, vol.36, n.6, pp.539. Disponível em: $<$ http://www.scielo.br/scielo.php?script=sci_arttext\&pid=S0100-736X2016000600539>. Acesso em: $15 \mathrm{de}$ Agosto de 2015.

22. Romao, M. F.; Santos, A. L.Qu. and Lima, F.C. Anatomia descritiva aplicada à cinesiologia e biomecânica básica dos músculos da cintura peitoral, estilopódio e zeugopódio do jacaré do papo amarelo. Cienc. Rural [online]. 2013, vol.43, n.4, pp.631-638. Disponível em: < http://www.scielo.br/scielo.php?script=sci arttext\&pid=S0103-84782013000400011> . Acesso em 15 de Setembro de 2016.

23. Rodrigues, R., G., Filadelpho, A. L. A.; Gomes, A. V. Brick, A. J. Describe the arm and shoulder muscles of the dog eating fox Cerdocyon thous. Revista cientifica eletrônica de medicina veterinária. 2013;21. Disponível em: < http://faef.revista.inf.br/imagens_arquivos/arquivos_destaque/e8SZe9azJeulzqs_2013-8-14-15-36-35. pdf $>$. Acesso em 02 de Fevereiro de 2016.

24. Santos AC, Bertassoli VM, Oliveira VC, Carvalho AF, Rosa RC, Mançanares CAF. Morfologia do ombro, braço e antebraço do quati (Nasua nasua). Biotemas, 2010;23(3):167-173. Disponível em: $<$ https://periodicos. ufsc.br/index.php/biotemas/article/viewFile/16016/14518 >. Acesso em 08 de Fevereiro de 2016.

25 Concha, I.; Adaro, L.; Borrón, C.; Altamirano, C. 2004. Consideraciones anatómicas sobre la musculatura intrínseca del miembro torácico del puma (Puma concolor). International Journal of Morphology, 22 (2): 121125. Disponível em: < http://www.scielo.cl/scielo.php?script=sci_arttext\&pid=S0717-95022004000200004 >. Acesso em 09 de Fevereiro de 2016.

26. St. Clair, LE. 1986. Músculos do carnívoro, In: Getty, R. D. V. M. (ed) Anatomia dos animais domésticos. V. 2. Guanabara Koogan, Rio de Janeiro. 2000 p. 
27. Santos AC, Bertassoli BM, Rosa RA, Carvalho AF, Marçanares CAF. Miologia comparada do membro torácico do mão-pelada (Procyon Cancrivorus, g. Cuvier, 1798). Revista da FZVA. Uruguaiana, 2010;17(2):262275 .

28. Done SH. Atlas colorido de anatomia veterinária: cão e gato. São Paulo: Manole, 2002.

29. Frandson RD, et al. Anatomia e Fisiologia dos Animais Domésticos. Rio de Janeiro: Guanabara Koogan, 1979. $429 \mathrm{p}$.

30. Tatarunas AC, Matera JM. Tenotomia artroscópica do músculo bíceps braquial em cadáveres de cães. Cienc. Rural. 2006;36(6):1824-1829. ISSN 1678-4596. Disponível em: < http://www.scielo.br/pdf/cr/v36n6/ a24v36n6.pdf $>$. Acesso em 18 de março de 2016. 